\title{
MOG antibodies, cortical encephalitis, and more food for thought studies
}

OPEN

Josep Dalmau, MD, PhD

Correspondence to: Dr. Dalmau:

jdalmau@clinic.ub.es

Neurol Neuroimmunol Neuroinflamm

2017;4:e330; doi: 10.1212/ NXI.0000000000000330
The concept that observations at the bedside have a unique power to inform translational research may seem old fashioned in an era where "omics" reign, but in fact, remains as valid as ever. In this issue of Neurology ${ }^{\circledR}$ Neuroimmunology \& Neuroinflammation, Ogawa et al. ${ }^{1}$ report a potential new clinical association of antibodies against myelin oligodendrocyte glycoprotein (MOG) and cortical encephalitis. The index patient was a 38-year-old man with a history of optic neuritis (ON), who developed loss of consciousness, a generalized tonic seizure with left-hand weakness due to Todd palsy, and MRI fluidattenuated inversion recovery (FLAIR)-increased signal in the right hemispheric cortex along with mild edema. After treatment with steroids and antiepileptics, he had full recovery and normalization of the MRI. This observation led the authors to retrospectively investigate 24 consecutive adult patients diagnosed with steroid-responsive encephalitis of unknown etiology, resulting in the identification of 3 additional patients with a phenotype described as "MOG-antibody-positive, benign, unilateral, cerebral cortical encephalitis with epilepsy." The unilateral cortical lesions were best identified by FLAIR sequences and appeared different from brain lesions previously reported with MOG-antibody-associated diseases such as acute demyelinating encephalomyelitis or from postepileptic changes in which diffusionweighted images show more prominent abnormalities. All 4 patients were male, with an age range of 23-39 years, 2 with past or concurrent development of $\mathrm{ON}$, and all recovered after treatment with steroids. The 3 patients whose CSF was available for studies had MOG antibodies and pleocytosis. However, different from patients with other MOG-antibody-associated disorders in whom the CSF usually shows increased levels of myelin basic protein (MBP), those with cortical encephalitis had normal MBP levels. This study brings up several interesting questions that will require further investigation. The authors suggest the possibility of co-existing autoantibodies to known or yet unknown antigens; all 4 patients were negative for antibodies against NMDA receptors, voltage-gated potassium channel complex proteins, glutamic acid decarboxylase, and thyroid antigens, but other neuronal autoantibodies were not investigated. Moreover, the current study focused on adult patients with steroid-responsive encephalitis; therefore, it is possible that this disorder may also occur in children or in some patients who are refractory to steroids. In summary, Ogawa et al. have made an important observation and have raised questions that need to be answered in larger cohorts of patients, including children, and using more comprehensive autoantibody studies.

Willis et al. ${ }^{2}$ describe 9 patients with relapsing MS treated sequentially with fingolimod and alemtuzumab, who developed substantial and unanticipated disease activity after starting alemtuzumab. In 8 of 9 patients, the disease activity included at least one clinical relapse in the first 12 months after initiating alemtuzumab, and all patients had MRI evidence of new disease activity. Median fingolimod washout period was 6 (4-10) weeks prior to the first alemtuzumab cycle. The patients were identified across 6 European Medical Centers in which a total of 174 patients had been treated with alemtuzumab; of these, 36 received fingolimod prior to administration of alemtuzumab. Therefore, the 9 patients of the current study represent $25 \%$ of the fingolimodalemtuzumab cohort. These findings are in contrast to a previous study ${ }^{3}$ of the same authors in which among 100 patients treated with alemtuzumab, only 4 developed $>1$ relapse in the 12 months after the initial infusion. The authors postulate that the unexpected disease activity in some patients of the fingolimod-alemtuzumab cohort was caused by sequestrated lymphocytes that remain hidden from the effects of alemtuzumab, which has a half-life of 7-21 days. After this period, surviving CD52-positive lymphocytes would egress from the lymph nodes causing the observed disease activity. The authors acknowledge a potential for selection bias, indicating the need for further studies including comprehensive immunophenotyping and trials addressing long-term outcomes of induction and escalation paradigms. The findings of this study suggest careful

From the ICREA-IDIBAPS, Hospital Clínic, University of Barcelona, Spain; and Department of Neurology, University of Pennsylvania. Funding information and disclosures are provided at the end of the editorial. Go to Neurology.org/nn for full disclosure forms.

This is an open access article distributed under the terms of the Creative Commons Attribution-NonCommercial-NoDerivatives License 4.0 (CC BY-NC-ND), which permits downloading and sharing the work provided it is properly cited. The work cannot be changed in any way or used commercially without permission from the journal. 
attention to the mechanism of action of individual therapies and sequential treatment effects.

Villoslada et al. $^{4}$ investigated the metabolomic profiles in 2 cohorts of patients with MS stratified into active or stable disease based on the 2 years of prospective clinical assessment and changes in the Expanding Disability Status Scale (EDSS). One of the cohorts was from a retrospective longitudinal study of 238 patients and 74 controls, and the other cohort was from a prospective study of 61 patients and 41 controls with serial serum samples. Findings revealed metabolomic signatures with high accuracy for classifying patients vs controls and patients with medium-to-high disability (EDSS $>3.0$ ). Sphingomyelin and lysophosphatidylethanolamine showed a more robust pattern in the time series analysis for discriminating between patients and controls. In addition, several other metabolites associated with more severe disease. The authors offer 3 possibilities to explain the source of the differences in lipid and amino acid levels, including, first, an increased activation of the immune system in which phospholipids and amino acids play a role as signaling molecules or regulators of membrane synthesis, cytokines, or lipid rafts. Second, the metabolomic signatures may reflect changes in CNS lipid composition caused by myelin destruction and astroglial proliferation, and third, an alternative possibility is that genetic susceptibility associated with MS may lead to changes in lipid and amino acid composition in serum, although none of the polymorphisms associated with MS have so far been found to be directly involved in lipid metabolism. The authors point out several limitations of the study, including, among others, the use of disease-modifying drugs and the absence of MRI monitoring. Last, although the identified classifiers of worsening disability were significant, the authors indicate that their diagnostic accuracy was not very high, suggesting that future studies should refine and improve them.

Moodley et al. ${ }^{5}$ performed a retrospective analysis of the clinical information of all patients meeting diagnostic criteria of chronic inflammatory demyelinating polyneuropathy in 2 neuromuscular units in KwaZulu-Natal (South Africa) between 2003 and 2015. Among 84 identified patients, 39 were HIV infected and $45 \mathrm{HIV}$ uninfected. Compared with the HIV-uninfected patients, those who were infected were more likely to be younger, female, have a monophasic progressive course, respond better to steroids, and be in remission within 12 months of corticosteroid initiation. CSF analysis showed that pleocytosis (usually mild) was more frequent in HIV-infected patients, and albumin-cytologic dissociation was present in $25 \%$ of the HIV-infected patients compared with $60 \%$ of the uninfected patients. Electrophysiologic findings were not significantly different between the 2 cohorts except for the degree and distribution of denervation on EMG: $12.8 \%$ of HIVinfected patients had denervation, mainly in proximal muscles vs $75 \%$ of uninfected patients who showed denervation mainly in distal muscles. Although the younger age and female preponderance in the group of HIV-infected patients is likely an artifact of the sample $(60 \%$ of HIV-infected patients in South Africa are young black females), the authors suggest that other differences among the 2 groups of patients may be due to different pathogenic mechanisms. The authors emphasize that most of the HIV-infected patients were in remission by 6 months, and that the short duration of corticosteroid therapy seems to be a safe and cost-effective option in this group of patients. Despite a careful differential diagnosis with acute inflammatory demyelinating polyneuropathy (AIDP), the authors indicate that the quick response to corticosteroids and the relatively monophasic course of the disease made AIDP a possibility in some cases.

In addition to these studies, this March issue of Neurology: Neuroimmunology \& Neuroinflammation contains 12 other interesting articles on a variety of topics, and an editorial comment on the use of maraviroc in progressive multifocal leukoencephalopathy and immune reconstitution inflammatory syndrome, which I hope will catch your attention.

\section{STUDY FUNDING}

No targeted funding.

\section{DISCLOSURE}

J. Dalmau is the editor of Neurology: Neuroimmunology \& Neuroinflammation; is on the editorial board for Neurology; holds patents for and receives royalties from Ma2 autoantibody test, NMDA receptor autoantibody test, GABA(B) receptor autoantibody test, GABA(A) receptor autoantibody test, DPPX autoantibody test, and IgLON5 autoantibody test; and receives research support from EUROIMMUN, NIH, Fundació CELLEX, and Instituto Carlos III (CIBERER and Fondo de Investigaciones Sanitarias). Go to Neurology.org/nn for full disclosure forms.

\section{REFERENCES}

1. Ogawa R, Nakashima I, Takahashi T, et al. MOG-antibodypositive, benign, unilateral, cerebral cortical encephalitis with epilepsy. Neurol Neuroimmunol Neuroinflamm 2017;4: e322. doi: 10.1212/NXI.0000000000000322.

2. Willis MD, Pearson O, Illes Z, et al. An observational study of alemtuzumab following fingolimod for multiple sclerosis. Neurol Neuroimmunol Neuroinflamm 2017;4:e320. doi: 10.1212/NXI.0000000000000320.

3. Willis MD, Harding KE, Pickersgill TP, et al. Alemtuzumab for multiple sclerosis: long term follow-up in a multi-centre cohort. Mult Scler 2016;22:1215-1223.

4. Villoslada P, Alonso C, Agirrezabel I, et al. Metabolomic signatures associated with disease severity in multiple sclerosis. Neurol Neuroimmunol Neuroinflamm 2017;4:e321. doi: 10.1212/NXI.0000000000000321.

5. Moodley K, Bill PLA, Patel VB. A comparative study of CIDP in a cohort of HIV-infected and HIV-uninfected patients. Neurol Neuroimmunol Neuroinflamm 2017;4: e315. doi: 10.1212/NXI.0000000000000315. 


\title{
Neurology \\ Neuroimmunology \& Neuroinflammation
}

\author{
MOG antibodies, cortical encephalitis, and more food for thought studies \\ Josep Dalmau \\ Neurol Neuroimmunol Neuroinflamm 2017;4; \\ DOI 10.1212/NXI.0000000000000330
}

This information is current as of March 2, 2017

\section{Updated Information \& Services}

References

Permissions \& Licensing

Reprints including high resolution figures, can be found at:

http://nn.neurology.org/content/4/2/e330.full.html

This article cites 5 articles, 0 of which you can access for free at: http://nn.neurology.org/content/4/2/e330.full.html\#\#ref-list-1

Information about reproducing this article in parts (figures,tables) or in its entirety can be found online at:

http://nn.neurology.org/misc/about.xhtml\#permissions

Information about ordering reprints can be found online: http://nn.neurology.org/misc/addir.xhtml\#reprintsus

Neurol Neuroimmunol Neuroinflamm is an official journal of the American Academy of Neurology.

Published since April 2014, it is an open-access, online-only, continuous publication journal. Copyright

Copyright (C) 2017 The Author(s). Published by Wolters Kluwer Health, Inc. on behalf of the American

Academy of Neurology. All rights reserved. Online ISSN: 2332-7812.

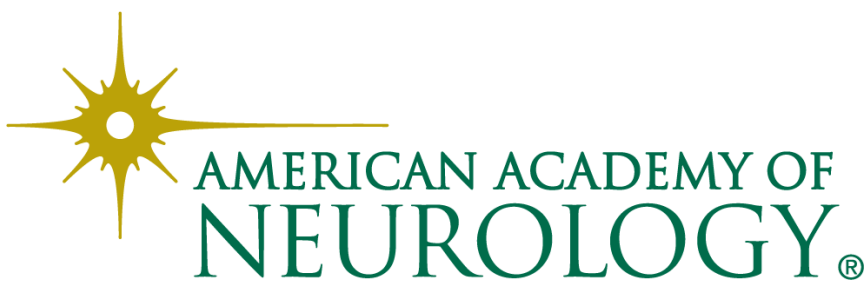

